\title{
Spontaneous Rupture of Hepatocarcinoma in a Patient without Previously Known Liver Disease
}

\author{
García-Orozco Víctor Hugo ${ }^{1, *}$, Velasco-Carbajal Daniel${ }^{2}$, López-Flores Juan $\mathrm{F}^{3}$, Solar-Aguirre Carlos ${ }^{4}$, and Ibarra-Ocampo \\ Carlos $\mathbf{M}^{5}$ \\ ${ }^{1}$ Cirujano general, Hospital Civil de Tepic “Dr. Antonio González Guevara”, Servicios de salud de Nayarit, Mexico \\ ${ }^{2}$ Cirujano oncólogo, Hospital Civil de Tepic “Dr. Antonio González Guevara”, Servicios de salud de Nayarit, Mexico \\ ${ }^{3}$ Maestro en ciencias de la salud, Banco de Leche Humana del Hospital civil de Tepic "Dr. Antonio González Guevara", Servicios de Salud de Nayarit, Mexico \\ "Jefe de servicio Cirugía General, Hospital Civil de Tepic "Dr. Antonio González Guevara", Servicios de salud de Nayarit, Mexico \\ ${ }^{5}$ Cirujano general, Hospital Civil de Tepic “Dr. Antonio González Guevara”, Servicios de salud de Nayarit, Mexico
}

*Corresponding author: García-Orozco Víctor Hugo, Cirujano general, Hospital Civil de Tepic “Dr. Antonio González Guevara”, Servicios de salud de Nayarit, Mexico, E-mail: victor-garcia.cirugia@hotmail.com

Received: 05 Jun, 2020 | Accepted: 19 Jun, 2020 | Published: 26 Jun, 2020

Citation: García-Orozco VH, Velasco-Carbajal D, López-Flores JF, Solar-Aguirre C, Ibarra-Ocampo CM (2020) Spontaneous Rupture of Hepatocarcinoma in a Patient without Previously Known Liver Disease. J Surg Open Access 6(5): dx.doi.org/10.16966/2470-0991.221

Copyright: (c) 2020 García-Orozco VH, et al. This is an open-access article distributed under the terms of the Creative Commons Attribution License, which permits unrestricted use, distribution, and reproduction in any medium, provided the original author and source are credited.

\section{Abstract}

The spontaneous rupture of hepatic neoplasms in Western countries has an incidence of less than $5 \%$. Hepatocarcinoma is the most common primary malignancy of liver and is one of the main solid tumors worldwide, being the $3^{\text {rd }}$ leading cause of cancer death. We present the case of a 20-year-old female patient operated on for sudden abdominal pain, with data on acute abdomen and hypovolemic shock, finding hemoperitoneum from a multisegmentary hemorrhagic hepatic lesion that required packing for damage control, and later, reoperation for definitive surgery and Histopathological analysis, resulting in hepatocarcinoma verified by immunohistochemistry.

Keywords: Acute abdomen; Hemoperitoneum; Hepatocarcinoma

\section{Introduction}

The spontaneous rupture of hepatic neoplasms in Western countries has an incidence of less than 5\% [1]. Hepatocellular carcinoma is one of the malignant neoplasms associated with worse prognosis, each year approximately 500,000 new cases are diagnosed and it is the third cause of cancer death [2]. Of the annual deaths attributed in records for this cause, at least 300,000 to 600,000 occur in China and in sub-Saharan countries [3], with a ratio male: female of 5:1, and a peak of incidence in the third and fourth decades in endemic areas [4]. Almost exclusively, this neoplasm is closely related to chronic liver disease, which has led to the development of cirrhosis. In recent years, there has been a significant increase in the incidence in Western countries, which has been attributed to the greater spread of the hepatitis C virus during the 60's and 70's as well as excessive alcohol consumption. About $90 \%$ of cases of hepatocellular carcinoma are based on known livers with established cirrhosis with hypervascular characteristic [5]. The risk of rupture of primary hepatic neoplasms has been well established previously, although the non-traumatic rupture of hepatocarcinoma is an infrequent form of presentation in our setting, finding prevalence in Western series that does not exceed 2.8-3.2\% [6]; however, it represents the third cause of death related to this tumor [4]. The exact mechanism of spontaneous rupture has not yet been defined, however it is proposed that there is a greater predisposition in tumors that invade the glisson's capsule [5], Recently, Zhu, et al. 29,30 postulated that spontaneous rupture of HCC may be related to vascular dysfunction. The vascular dysfunction results from degeneration of elastin and degradation of type IV collagen, rendering the blood vessels stiff and weak and causing them to split easily when the vascular load increases from hypertension or minor trauma [7].

\section{Case Report}

A 20 -year-old female patient with no relevant medical history, admitted to the emergency department with severe, diffuse, sudden abdominal pain, which is subsequently located in the pelvic cavity, initially assessed by the gynecology service, which performs pelvic ultrasonography in which free liquid is observed in cavity, as well as clinical data of hypovolemic shock with acute abdomen. Surgical intervention is performed due to the suspicion of a ruptured ovarian cyst, with an approximate 2,000 hemoperitoneum without evidence of bleeding in the pelvic organs. Therefore, evaluation by general surgery service is requested, performing exploratory laparotomy, observing bleeding liver lesion in segment III and IV with features of a ruptured hepatic abscess, with active profuse bleeding throughout the hepatic surface, without evidencing an abscess capsule, performing haemostasis, washing and cavity drainage, as well as packing for 
damage control by critical condition of the patient, which is admitted to the intensive care unit for surveillance and comprehensive support of the state of shock. At 12 hours postoperatively the patient persists with active bleeding data, vasopressors requirement, so she enters again for exploration, finding active bleeding in hepatic parenchyma with abundant clots in segments mentioned above, inferior vena cava tear of approximately $3 \mathrm{~mm}$, performing partial hepatectomy of the affected segments and vascular repair without eventualities. The patient returns to the intensive care unit for surveillance and comprehensive support, without evidence of active bleeding. The patient evolves satisfactorily, remaining hemodynamically stable, with remission of the state of shock and absence of active bleeding. In the histopathological report, malignant epithelial neoplasia with a solid, trabecular, pseudoglandular and sinusoidal growth pattern was identified microscopically with foci of macrovesicular steatosis; multiple intratumoral vessels and cells that demonstrate nuclear pleomorphism, multinucleation, and broad eosinophilic granular cytoplasm (Figure 1), as well as areas of recent extensive necrosis and hemorrhage, without being able to identify normal liver tissue. Given the lack of risk factors as a background for malignant neoplasms, an immunohistochemical analysis of samples in which the Hepar 1 label was negative (Figure 2) was performed, with supplementation being necessary with additional markers CK8/18 (Figure 3), CD10 (Figure 4) and CEA (Figure 5), which are positive for hepatocellular carcinoma. The patient is delivered by improvement with follow-up in consultation and sending to medical oncology to continue diagnostic protocol with extension studies and specialized treatment.

\section{Discussion}

Hepatocellular carcinoma constitutes the most frequent malignant primary neoplasm of the liver, and although the spontaneous rupture constitutes a complication that reaches percentages of up to 10.5$14.5 \%$ in series belonging to Asian countries [8], the non-traumatic rupture in the middle Western is an infrequent presentation (2.8$3.2 \%)$ [6]. The reports made so far are based on the follow-up of patients with a diagnosis of chronic liver disease. Paradoxically, the spontaneous rupture constitutes up to $50 \%$ of the manifestations in presentation of benign neoplasms such as hepatocellular adenoma [6]; hemangiomas has a mortality close to $75 \%$ when their presentation is by spontaneous rupture, starting with a rupture towards the inside of the tumor and subsequent increase in pressure, which leads to a rupture of the capsule and subsequent bleeding [8]. The development of hemoperitoneum secondary to the spontaneous rupture of hepatic tumors entails a physiopathological chain that constitutes a challenge to the management of critically ill surgical patients, since the subcapsular

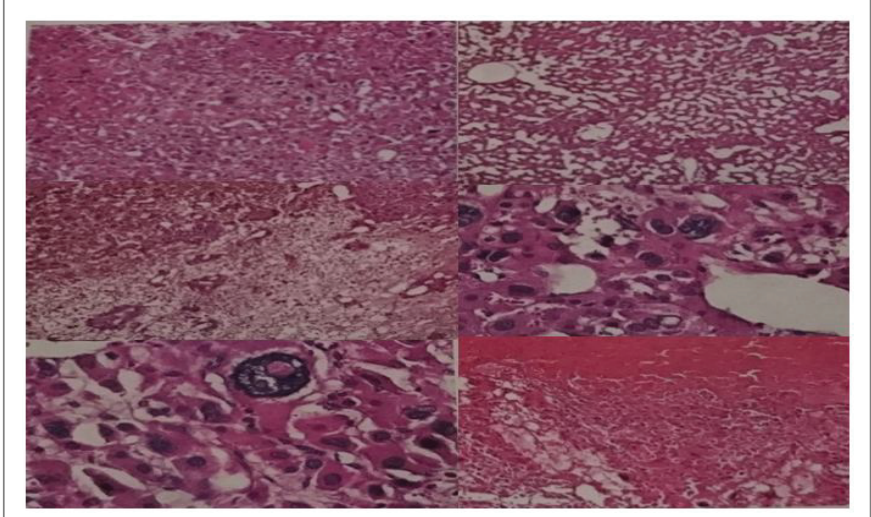

Figure 1: Histopathological cuts of initial revision. location of hepatocellular carcinoma, the size that is reached and the hypervascular character as well as the increase in portal venous pressure due to tumor compression or direct invasion [6], implies the need for aggressive action to rescue these patients, since when the rupture occurs spontaneously in patients without suspicion of liver injury, the outcome is usually catastrophic [9]. The main symptoms when a rupture occurs are: abdominal pain (66-100\%) and hypovolemic shock (33-99\%) [10], peritoneal irritation due to bleeding is not as common in cases of rupture of a deeper lesion, which does not interrupt the liver capsule [11]. Complementary imaging and paraclinical studies should not imply a delay in the treatment of hemodynamically unstable patients in whom laparotomy should be performed urgently. Because the probability of diagnosing hepatocarcinoma is directly related to the degree of hepatic involvement, differential diagnoses should be taken into account in the presence of non-traumatic hemoperitoneum in patients in whom previous chronic liver diseases were not known [12]. The infrequent presentation of hemoperitoneum in patients not known with chronic hepatopathies in our environment,

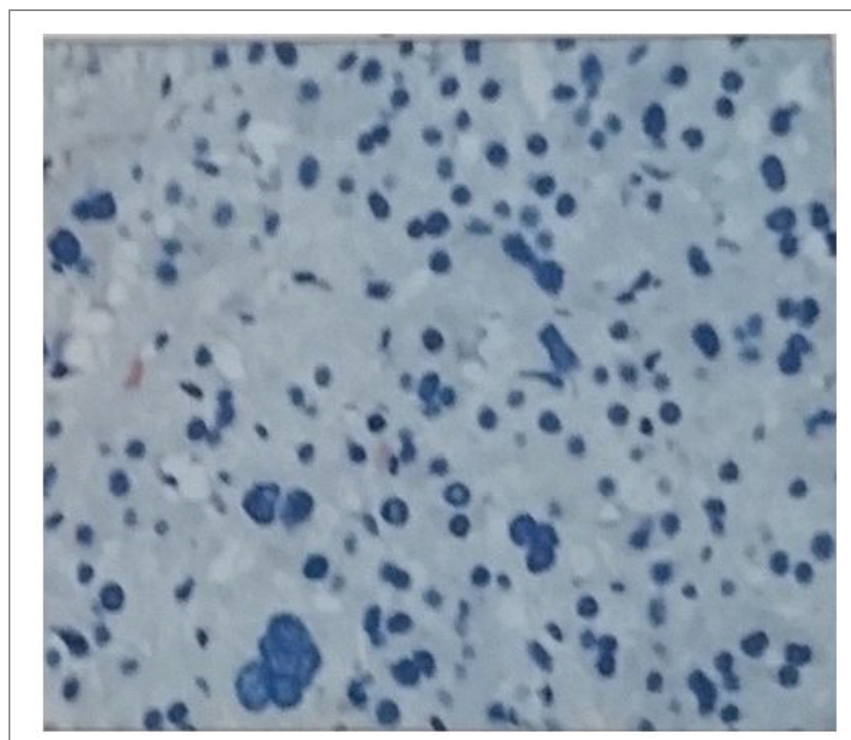

Figure 2: Hepar 1 immunohistochemistry.

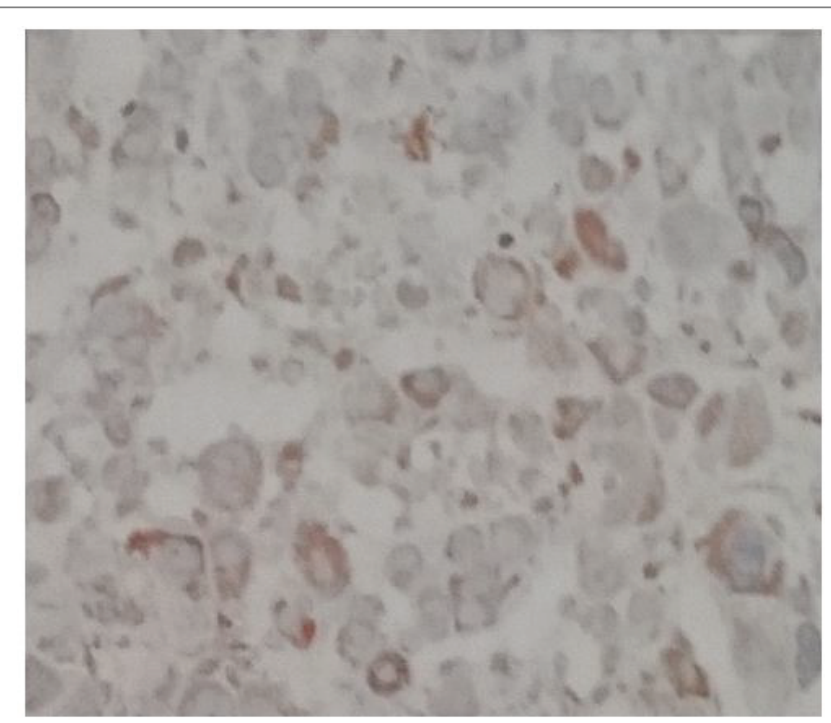

Figure 3: Immunohistochemistry CK8/18. 


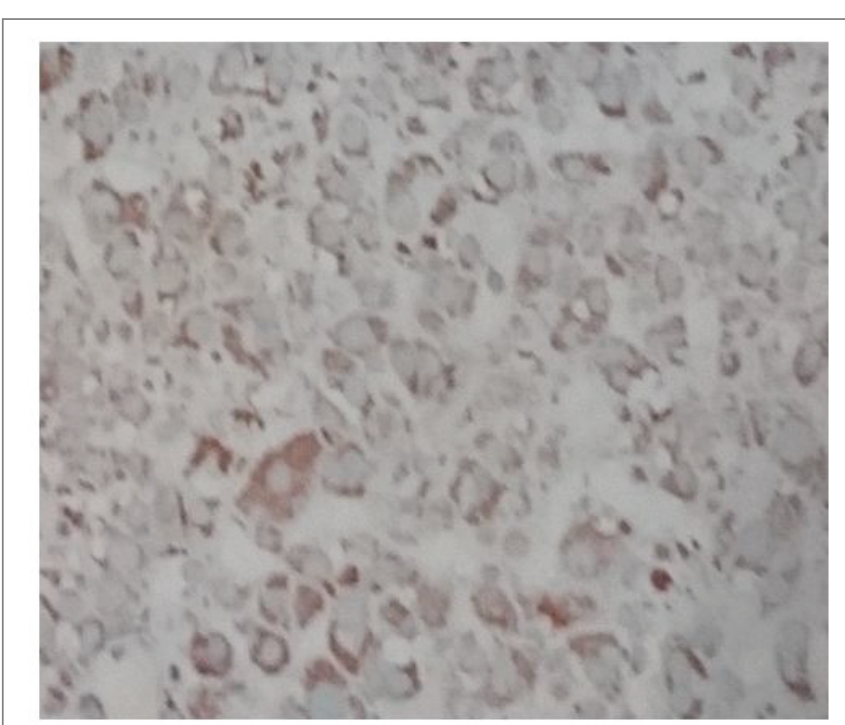

Figure 4: Immunohistochemistry CD10.

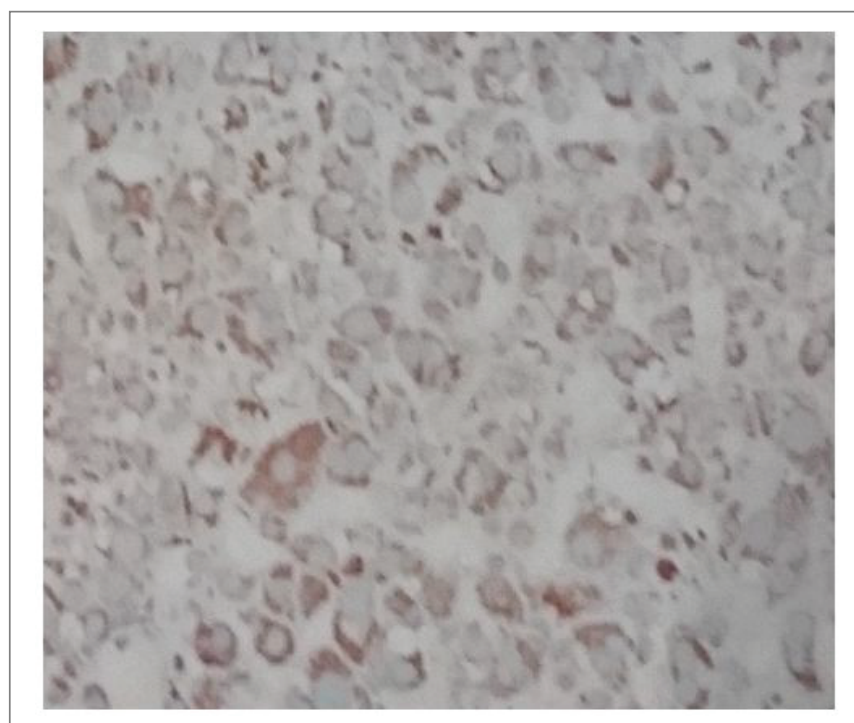

Figure 5: Immunohistochemistry CEA.

forces us to consider the close monitoring of this type of cases, with complementary studies once the stabilization of the patients has been achieved; histopathological monitoring whenever the clinical, the antecedents and the transoperative findings present discrepancies before the etiological diagnosis of urgency. Screening programs should be applied to all patients with a history of chronic liver disease regardless of its etiology, since the risk of developing hepatocarcinoma has an annual incidence of approximately $3-4 \%$ in this type of patient [13]. We must consider that hemangiomas, adenomas and hepatocarcinomas are the 3 hepatic neoplasms most likely to present this picture [14], the urgent laparotomy being necessary in most of the occasions before the seriousness with which they appear. Despite the aforementioned, there are reports with a small percentage of hepatocarcinoma on healthy livers, where the clinical manifestations are usually nonspecific and usually go unnoticed in patients who are outside the age range of presentation, which generally ranges from 60 to 70 years of life [15]. Patients with no relevant personal history for the suspicion of malignancy should be screened with histopathological reports, and, as explained in the present case, immunohistochemical complementation. It is important to point out that there is no single marker to clarify diagnostic decisions [16]. Among the markers studied in this patient are HEPAR-1, which has sensitivity between 80 and $90 \%$ with a specificity of $95 \%$ for the determination of the hepatocyte origin of the lesion [17]. The alpha feto protein, despite its wide utility in digestive tumors, has a high percentage of false negatives, and in the case of hepatocarcinoma, only between 25 and 50\% present immunohistochemical expression [16]. Carcinoembryonic antigen presents a cross-reaction with hepatic monoclonal antibodies at the level of biliary glycoproteins, which allows a characteristic canalicular immunoreactivity of tumors of hepatic origin, being highly specific, but not very sensitive (95 and 50\% respectively) [16]. The Common Antigen of Acute Lymphoblastic Leukemia (CD10), identifies a canalicular pattern similar to carcinoembryonic antigen reaching a specificity of up to $95 \%$, with a variability in sensitivity according to tumor differentiation (85\% in well-differentiated neoplasms and $25 \%$ in the little differentiated) [16]. Cytokeratins and epithelial markers have shown great utility in allowing differentiation, according to their percentage of presentation to different tumors, being common that hepatocarcinomas present expression of cytokeratins CK8 and CK18, but in most do not express CK7, which is It occurs most frequently in the biliary epithelium and metastatic carcinomas [16].

\section{Conclusions}

The low frequency of presentation of spontaneous hemoperitoneum from liver tissue in patients without a history of hepatopathy, and in whom the origin has been ruled out in other organs, forces us to control hemorrhage at an early stage by emergency laparotomy, with the initial goal is homeostasis [15] for maintaining the hemodynamic stability and prevention of the triad of death, and a definitive control was subsequently carried out with the necessary resources for the planned surgical approach. In view of the statistical increase in hepatocellular carcinoma in our environment, it is necessary to consider taking biopsies for histopathological study and the follow-up of cases where there are discrepancies regarding antecedents, presentation and transoperative findings, since the omission of this can lead to unnoticed diagnosis, with the risk of early invasion of ruptured tumors, which is one of the factors that negatively influence the short-term prognosis and survival of patients [16], which shows the aggressive nature and poor forecast before this form of presentation $[17,18]$.

\section{Conflict of Interests}

It is considered that there are no conflicts of interest between the proponents and participants in the present work.

\section{Acknowledgments}

To the staff of the civil hospital "Dr. Antonio González Guevara" for the facilities for patient care and data collection.

\section{References}

1. Rodríguez RMJ, Martínez JMA, Artacho GS, Bellido CB, Marín LM (2009) Hepatocarcinoma primario no conocido como causa de hemoperitoneo espontáneo. Rev Esp Enferm Dig 101: 506-519.

2. Vieito NP, Montañés AG, Blanco MD (2014) Hepatocarcinoma: estado actual. Galicia Clin 75: 171-181.

3. Ferenci P, Fried M, Labrecque D, Bruix J, Sherman M, et al. (2009) Carcinoma Hepatocelular (CHC): Una perspectiva mundial. Guía mundial de la organización global de la gastroenterología. World Gastroenterology Organisation. 
4. Rabie ME, Alqahtani SAJ, Hakeem IE, Qahtani ASA, Alhagawi YA et al. (2017) Ruptured hepatocellular carcinoma: Management options. Saudi Surg J 5: 27-34.

5. Bassi N, Caratozzolo E, Bonariol L, Ruffolo C, Bridda A, et al. (2010) Management of ruptured hepatocellular carcinoma: Implications for therapy. World J Gastroenterol 16: 1221-1225.

6. Fernández-Ruiz M, Guerra-Vales JM, Llenas-García J, Delgado-García JM, Gómez-Pellico C, et al. (2008) Hemoperitoneo como forma de presentación del carcinoma hepatocelular: experiencia de tres casos con rotura tumoral espontánea y revisión de la literatura. An Med Interna (Madrid) 25: 1-4.

7. Lai ECH, Lau WY (2006) Spontaneous Rupture of Hepatocellular Carcinoma: A Systematic Review. Arch Surg 141: 191-198.

8. Paredes MPG, Fernández JM, González AM, García JLP (2016) Rotura espontánea de hemangioma hepático no conocido. Rev Esp Enferm Dig 108: 431.

9. Aoki T, Kokudo N, Matsuyama Y, Izumi N, Ichida T, et al. (2014) Prognostic Impact of Spontaneous Tumor Rupture in Patients with Hepatocellular Carcinoma: An Analysis of 1160 Cases From a Nationwide Survey. Ann Surg 259: 253-542.

10. Sahu SK, Chawla YK, Dhiman RK, Singh V, Duseja A, et al. (2019) Rupture of Hepatocellular Carcinoma: A Review of Literature. J Clin Exp Hepatol 9: 245-256.
11. Hawatmeh A, Jumean K, Arqoub AA, Shaaban H (2016) Spontaneous rupture of hepatocellular carcinoma. Hepatoma Res 2: 103-106.

12. Yang $\mathrm{H}$, Chen $\mathrm{K}$, Wel $\mathrm{Y}$, Liu F, Li H, et al. (2014) Treatment of spontaneous ruptured hepatocellular carcinoma: A single-center study. Peak J Med Sci 30: 472-476.

13. Senent SG, Raposo CG, Cabral JMS (2007) Guía para el diagnóstico, estatificación y tratamiento del hepatocarcinoma. Med Clin (Barc) 128: $741-748$.

14. Espil G, Larrañaga N, Villarroel ND, Oyarzun A, Matzke G, et al. (2015) Hemorragia abdominal espontánea: evaluación por imágenes. Rev Argent Radiol 79: 86-94.

15. Pinal-García DF, Nuño-Guzmán CM, Gómez-Abarca A, Corona JL, Espejo I (2018) Spontaneous Rupture of Hepatocellular Carcinoma in a Young Patient with Fatal Outcome. Case Rep Gastroenterol 12: 19-26.

16. Gallego JJS, Santos AP (2010) Caracterización inmunohistoquímica de los tumores hepáticos. Una aproximación diagnóstica al diagnóstico de hepatocarcinoma. Revisión Técnica Diagnóstica.

17. Trigueros JPJ (2015) Oncología: Hepatocarcinoma. Revista Medica De Costa Rica Y Centroamerica 75: 125-127.

18. Martínez DTE, Peña PD, Merino JF, Dávila MP (2016) Rotura de hepatocarcinoma y diseminación tumoral masiva precoz. Cir Esp 94: 237 